\title{
Effect of Elastic Band Exercise on the Plantar Pressure and Maximum Muscle Strength in Female University Students Wearing High Heels
}

\author{
Bum-Chul Jung $\cdot$ Kyung-Tae Yoo ${ }^{\dagger} \cdot$ Young-Hwan Kim
}

Dept. of Physical Therapy, Graduate School, Namseoul University

${ }^{1}$ Dept. of Sports Medicine, Graduate School Physical Education, KyungHee University

Received: July 27, 2017 / Revised: July 28, 2017 / Accepted: August 18, 2017

(c) 2017 J Korean Soc Phys Med

\section{| Abstract |}

PURPOSE: The purpose of this study was to investigate the effect of the elastic band and stretching exercise program on ankle joint maximal voluntary isometric contraction (MVIC) and plantar pressure in high-heel wearing women in their 20s.

METHODS: Twenty women in their twenties were randomly assigned to the experimental group $(\mathrm{n}=10)$ and the control group $(\mathrm{n}=10)$. The experimental group $(\mathrm{n}=10)$ performed the elastic band exercise program, while the control group $(n=10)$ performed the stretching exercise program. Both exercise programs were performed three times a week for a total of four weeks. The BTE Primus RS was used in order to measure the ankle joint MVIC during dorsiflexion, plantar flexion, inversion, and eversion. Maximum pressure $\left(\mathrm{N} / \mathrm{cm}^{2}\right)$, average pressure $\left(\mathrm{N} / \mathrm{cm}^{2}\right)$ were measured using the Pedoscan. SPSS v. 21.0 software was used for all statistical analyses in this study.

RESULTS: The measurement of the ankle joint's MVIC

†Corresponding Author : taeyoo88@nsu.ac.kr

This is an Open Access article distributed under the terms of the Creative Commons Attribution Non-Commercial License (http://creativecommons.org/licenses/by-nc/3.0) which permits unrestricted non-commercial use, distribution, and reproduction in any medium, provided the original work is properly cited. revealed that in inversion, a significant change in both feet was seen in both the experimental and control groups. In eversion, there was a significant change in both feet only in the experimental group. In terms of the rest of the results, no significant changes were visible. With regard to the plantar pressure, no significant results were seen for either foot in the comparison between or within the groups.

CONCLUSION: Exercise program using elastic band and exercise program using stretching were effective on MVIC of ankle joint muscles, although it had no effect on changes of plantar pressure.

Key Words: Ankle, Exercise program, Muscle strength, Plantar pressure, Shoes

\section{Introduction}

In modern society, shoes are frequently seen as a tool for aesthetic expression and, as such, young women often show a preference for wearing high heels (Ryu, 2010). In particular, high heels are favored in terms of fashion due to reflecting trends as well as increasing the wearer's height (Ko et al., 2009). Furthermore, high heels have been suggested to assert the importance of individuality and, due to increasing trends of confident women, they have 
become a "must have" item for showcasing the independent and strong female form (Song et al., 2009).

However, high heels reduce both the movement of the center of gravity and the area of the support surface, which results in not only unnecessary and excessive activity of the lower leg muscles during walking, but also lower back pain, ankle pain, arthritis, and other musculoskeletal disorders (Franklin et al., 1995; Yoon et al., 2010). Additionally, the wearing of high heels not only degrades the wearer's ability to receive and send proprietary sensory information, but also damages the afferent feedback system and negatively affects the neuromuscular control that helps to maintain balance (Gribble et al., 2004). Furthermore, depending on the height of the heel, the load on the muscle is changed, and an increased multi-directional change in the center of body mass (CBM) causes instability when walking (Lee et al., 2001). Opila et al. (1988) report that when wearing high heels, the center of gravity is shifted anteriorly for the external meatus and greater trochanter during standing, while for the femoral epicondyle and the lateral malleolus, it is shifted posteriorly. In other words, when standing in high heels, the wearer's center of gravity is shifted anteriorly for the upper body and posteriorly for the lower body.

Plantar pressure is the pressure applied to the whole of the foot as well as to specific areas during movement and the performance of the functional activity of daily life. As such, it is an area of significant clinical interest (Dowling et al., 2001; Yoon et al., 2009). Plantar pressure that deviates from the normal range causes not only physiological disorder, but also musculoskeletal injury, while repeated disproportionate weight bearing in the lower limbs will eventually cause postural misalignment (Gravante et al., 2003).

A previous study that examined the relationship between high heels and plantar pressure reported that the increased pressure placed on the ball of the feet when wearing high heels was also a source of immense discomfort (Song et al., 2009). The observation of the pressure distribution according to the heel height during walking as well as the shape of the foot showed that at maximum pressure, the height of the high heel was medium and there was minimal restriction. When the height of the high heel was at its lowest, the velocity of the gait appeared to be at its fastest, with excellent absorption of shock (Shin, 1997). Furthermore, when standing in high heels, in order to adapt to the resultant mechanical changes to the musculoskeletal system of the foot and ankle, the mechanism of balance control changes in a specific way. This change is associated with decreased balance function and an increased risk of falls (Kim and Lee, 2007).

Balance maintains both the center of gravity and the base of support. It also provides the ability to move, and this equilibrium reaction is what allows humans to return to a centralized position on a basal plane using muscle activity and muscle production (Yaggie and McGregor, 2002). In order to maintain the body's balance, whilst moving accordingly, sufficient force must be generated to ensure stability. If the muscles surrounding the ankle joint are not able to achieve stability, the joint becomes unstable and postural fluctuation increases, which eventually reduces the ability to maintain balance (Clifford and Holder-Powell, 2010). In order to control balance, a sufficient range of joint motion and muscle strength are required (Lee, 2008).

An elastic band is a band characterized by elasticity and, therefore, resistance exercise is possible in all directions. Movement is made in opposing directions to the contraction of the band, which increases the muscular strength expenditure without any added gravitational effects (Seo, 2005). Furthermore, the method is convenient as well as involving little risk of injury and no locational limitations (Jung and Joo, 2003). It includes many positives such as strengthening muscle, increasing endurance, promoting proprioceptive function, and preventing bone atrophy (Woodall and Welsh, 1990). Recently, there have been many studies regarding the effect of high heels on the body 
(Gefen et al., 2002; Lee et al., 2001; Lee et al., 2009; Park, 2016; Yoon et al., 2010).

However, only a limited number of prior studies investigating the effect of elastic band exercise on the maximum voluntary isometric contraction (MVIC) and plantar pressure in female university students who wear high heels have been conducted. As such, this study divides women in their 20s who wear high heels into two groups. Each group was then instructed to perform either an elastic band or stretching exercise program, and the effect on the MVIC and plantar pressure was investigated.

\section{Methods}

\section{Subject}

The subjects involved in this study were 20 female students aged in their 20s who are currently enrolled in "N" university, Chungnam, South Korea. The subjects were thoroughly informed of the nature of the study, and they all provided voluntary written consent after confirming their complete understanding. At the time of the study, all the subjects were confirmed to not currently experience and have no history of ankle instability. A questionnaire regarding high heels and pain (Park, 2016) has been modified to fit the aims of this study. Physically healthy women capable of exercise who wore heels higher than $5 \mathrm{~cm}$ for more than 8 hours a day and more than 4 times a week were selected as subjects. The subjects were examined and cleared in terms of their ability to participate in exercise. Through randomized distribution, 10 subjects were assigned to the experimental group which underwent the elastic band exercise program, and 10 subjects were assigned to the control group undergoing the stretching exercise program. During the experiment, subjects were instructed not to wear high heels and the elastic band and stretching exercise program referenced the exercise program used in Lee et al. (2016).

\section{Experimental Method}

\section{1) Elastic Band Exercise Program (Experimental Group)}

After performing warm-up exercises, the main exercise was performed, followed by a concluding exercise. The program was performed three times a week for a total of four weeks. The warm-up exercise was not influenced by the set, while the performance of the elastic band exercise was increased to five times per week (Table 1). The intensity of the elastic band exercise was set according to the evidence provided in a previous study (Lee et al., 2016) conducted on healthy adults, and a blue elastic band was used.

Table 1. Elastic-band exercise program

\begin{tabular}{lllc}
\hline Level & Item & Intensity & Time \\
\hline Warm-Up & Pelvic/Quadriceps/Popliteus/ & Left (15 s), Right (15 s) & $5 \mathrm{~min}$ \\
& Tibialis Anterior Stretching & $30 \mathrm{~s} / \mathrm{set}$ & \\
Main Exercise & Elastic-Band Exercise & & $20 \mathrm{~min}$ \\
& Leg Up and Down & & \\
& Squat & & \\
& Lunge & & $5 \mathrm{~min}$ \\
\hline Cool-Down & Plantarflexion/Dorsiflexion & & Left (15 s), Right $(15 \mathrm{~s})$ \\
\hline
\end{tabular}


Table 2. Stretching exercise program

\begin{tabular}{|c|c|c|}
\hline Item & Intensity & Time \\
\hline \multicolumn{3}{|l|}{ Stretching } \\
\hline \multicolumn{3}{|l|}{ Lunge } \\
\hline Pelvic Muscle Stretching & Left (15 s), Right (15 s) & \\
\hline Quadriceps Stretching & 5 set & $30 \mathrm{~min}$ \\
\hline Popliteus Stretching & $2 \mathrm{~min} / \mathrm{set}$ rest & \\
\hline \multicolumn{3}{|l|}{ Gastrocnemius Stretching } \\
\hline Peroneus, Tibialis Anterior & & \\
\hline
\end{tabular}

\section{2) Stretching Exercise Program (Control Group)}

The same warm-up exercises were performed as for the experimental group, after which the stretching exercise program was performed. The program was performed three times a week for a total of four weeks. In the control group, no changes were made to the set (Table 2).

\section{Measurement Apparatus}

\section{1) General Characteristics}

This study used a body composition analyzer (Inbody 720 , BioSpace, South Korea) to measure the general characteristics of the subjects.

\section{2) Measurement of the Ankle MVIC}

This study used a BTE Primus RS system (Baltimore Therapeutic Equipment Company, Hanover, MD, USA) to measure the subjects' ankle MVIC. The MVIC of the ankle during dorsiflexion, plantarflexion, inversion, and eversion was measured whilst the subject was in a seated position. The PRIMUS RS was designed to examine isometric, isotonic, and isokinetic exercise ability. Also, through the cable system, PNF exercise therapy as well as 200 on site examinations can be conducted in the actual environment. It is structured as one unit with an internal computer monitor and a chair used for evaluation. Additional attachments and basic sports equipment are also included to aid with on site evaluations.

\section{3) Measurement of the Plantar Pressure}

A plantar pressure analyzer (Pedoscan, Diers, Germany) was used to measure the subjects' plantar pressure (Fig. 1). The subjects were instructed to comfortably stand
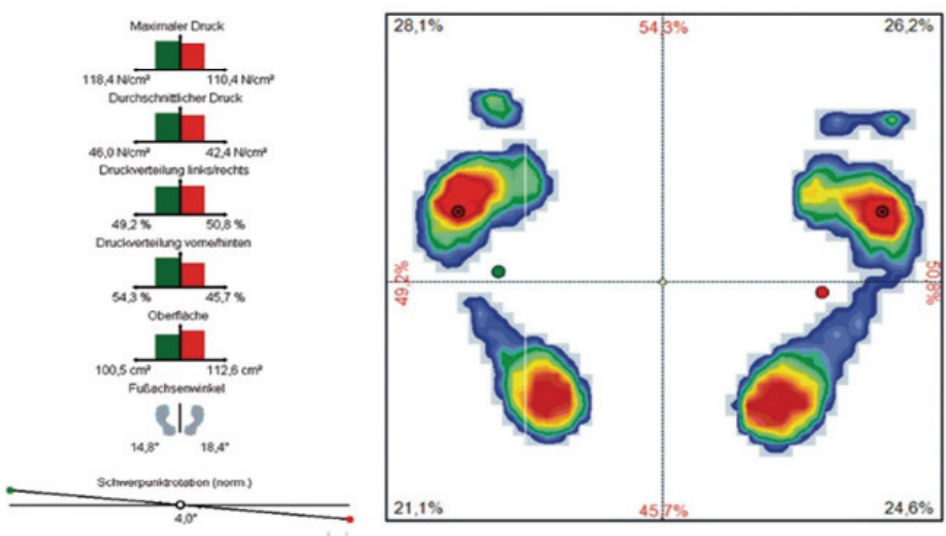

Fig. 1. Pedoscan 
barefoot with their feet shoulder width apart on the machine for a duration of 15 seconds. The maximum pressure $\left(\mathrm{N} / \mathrm{cm}^{2}\right)$, average pressure $\left(\mathrm{N} / \mathrm{cm}^{2}\right)$ was all measured a total of 3 times and the mean value was used.

\section{Data Analysis}

SPSS v. 21.0 software was used for all the statistical analyses in this study. The mean (M) and standard deviation (SD) were calculated and compared for each variable. The normal distribution of the characteristics of the data were confirmed using the Kolmogorov-Smirnov test. The degree of the ankle MVIC and the change in plantar pressure between the elastic band exercise group and the stretching exercise group were determined using the independent $\mathrm{t}$-test. The pre- and post-intervention comparison of the plantar pressure and ankle MVIC within each group was conducted using the paired t-test. Statistical significance was set at $\alpha=.05$.

\section{Results}

\section{General Characteristics of the Subjects}

The general characteristics of the subjects who participated in this study are presented in Table 3. All the subjects were female. Each group consisted of ten subjects, with no particular differences between the groups. There were no significant differences in terms of height, weight, or age between the two groups $(p>.05)$.

\section{Change in the Ankle MVIC}

The results of the BTE measurement of the ankle MVIC showed that in terms of plantarflexion and dorsiflexion, both the experimental and control groups did not experience any significant changes for either the left or the right foot $(p>.05)$. A comparison between the groups also showed that there was no change in the results ( $p>.05)$ (Table 4). With regard to inversion, a comparison within the groups showed that both the experimental and control groups experienced significant changes in both feet $(\mathrm{p}<.05)$; however, there was no degree of change upon comparison between the groups $(p>.05)$ (Table 4$)$. With regard to eversion, within the experimental group there was a significant change in both feet $(p<.05)$. In the control group, there were no significant changes seen for either foot. A comparison between the groups revealed no differences $(p>.05)$ (Table 4).

\section{Change in the Plantar Pressure}

The Pedoscan apparatus used to measure the subjects' plantar pressure revealed no significant changes in the maximum pressure, average pressure for either foot $(p>.05)$. Additionally, no significant changes were seen in the comparison between the groups or the comparison within the groups $(p>.05)$ (Table 5).

\section{Discussion}

This study investigated the effect of stretching and elastic band exercise on the MVIC and plantar pressure in women in their $20 \mathrm{~s}$ who often wear high heels. After measuring the ankle joint MVIC for this study, it was observed that in the experimental group, there was a post-intervention

Table 3. General characteristics of the subjects $(n=20)$

\begin{tabular}{lccc}
\hline & Experimental Group $(\mathrm{n}=10)$ & Control Group $(\mathrm{n}=10)$ & $\mathrm{P}$ \\
\hline Height $(\mathrm{cm})$ & $161.25 \pm 3.98$ & $162.84 \pm 9.93$ & .26 \\
Weight $(\mathrm{kg})$ & $55.01 \pm 3.70$ & $54.55 \pm 9.60$ & .06 \\
Age (years) & $21.50 \pm .70$ & $21.50 \pm .84$ & .44 \\
\hline
\end{tabular}


Table 4. Comparison between the experimental group and the control group (BTE; $n=20$ )

\begin{tabular}{|c|c|c|c|c|c|c|}
\hline & & Group & Pre & Post & $\mathrm{t}$ & $p$ \\
\hline \multirow{8}{*}{$\mathrm{Lt}$} & \multirow{2}{*}{$\begin{array}{l}\text { Plantar Flexion } \\
(\% \text { MVIC) }\end{array}$} & Experimental & $14.76 \pm 6.13$ & $15.78 \pm 4.45$ & \multirow{2}{*}{-.65} & \multirow{2}{*}{.53} \\
\hline & & Control & $18.52 \pm 7.39$ & $17.51 \pm 4.49$ & & \\
\hline & \multirow{2}{*}{$\begin{array}{l}\text { Dorsi Flexion } \\
(\% \mathrm{MVIC})\end{array}$} & Experimental & $16.94 \pm 6.14$ & $17.57 \pm 9.03$ & \multirow{2}{*}{.68} & \multirow{2}{*}{.50} \\
\hline & & Control & $18.44 \pm 6.87$ & $23.51 \pm 12.11$ & & \\
\hline & \multirow{2}{*}{$\begin{array}{l}\text { Inversion } \\
(\% \mathrm{MVIC})\end{array}$} & Experimental & $9.92 \pm 5.41$ & $26.49 \pm 15.03^{\dagger}$ & \multirow{2}{*}{-1.84} & \multirow{2}{*}{.82} \\
\hline & & Control & $14.89 \pm 6.68$ & $21.68 \pm 7.24^{\dagger}$ & & \\
\hline & \multirow{2}{*}{$\begin{array}{l}\text { Eversioin } \\
(\% \mathrm{MVIC})\end{array}$} & Experimental & $9.08 \pm 4.81$ & $13.51 \pm 5.23^{\dagger}$ & \multirow{2}{*}{-.73} & \multirow{2}{*}{.45} \\
\hline & & Control & $11.73 \pm 5.16$ & $13.72 \pm 5.69$ & & \\
\hline \multirow{8}{*}{ Rt } & \multirow{2}{*}{$\begin{array}{l}\text { Plantar Flexion } \\
\text { (\%MVIC) }\end{array}$} & Experimental & $12.92 \pm 6.22$ & $13.38 \pm 3.66$ & \multirow{2}{*}{-.31} & \multirow{2}{*}{.76} \\
\hline & & Control & $18.95 \pm 4.79$ & $18.62 \pm 4.32$ & & \\
\hline & \multirow{2}{*}{$\begin{array}{l}\text { Dorsi Flexion } \\
(\% \mathrm{MVIC})\end{array}$} & Experimental & $17.59 \pm 5.74$ & $16.34 \pm 5.98$ & \multirow{2}{*}{.55} & \multirow{2}{*}{.59} \\
\hline & & Control & $18.92 \pm 6.83$ & $20.65 \pm 8.93$ & & \\
\hline & Inversion & Experimental & $8.69 \pm 2.06$ & $24.97 \pm 13.14^{\dagger}$ & \multirow[b]{2}{*}{-1.92} & \multirow[b]{2}{*}{.71} \\
\hline & (\%MVIC) & Control & $16.39 \pm 8.07$ & $22.94 \pm 6.38^{\dagger}$ & & \\
\hline & \multirow{2}{*}{$\begin{array}{l}\text { Eversioin } \\
(\% \mathrm{MVIC})\end{array}$} & Experimental & $9.15 \pm 2.71$ & $14.85 \pm 7.15^{\dagger}$ & \multirow{2}{*}{-.47} & \multirow{2}{*}{.68} \\
\hline & & Control & $13.85 \pm 6.59$ & $18.12 \pm 4.84$ & & \\
\hline
\end{tabular}

$\mathrm{Lt}=$ Left, Rt=Right, ${ }^{+}$Significant differences between pre-test and post-test,

$* p<.05$ (=Significant differences between Experimental group and control group)

Table 5. Comparison between the experimental group and the control group (Pedoscan; $n=20$ )

\begin{tabular}{|c|c|c|c|c|c|c|}
\hline & & Group & Pre & Post & $\mathrm{t}$ & $p$ \\
\hline \multirow{4}{*}{$\mathrm{Lt}$} & \multirow{2}{*}{$\begin{array}{c}\text { Maximum pressure } \\
\left(\mathrm{N} / \mathrm{cm}^{2}\right)\end{array}$} & Experimental & $2.53 \pm .81$ & $2.29 \pm .66$ & \multirow{2}{*}{-.33} & \multirow[t]{2}{*}{.75} \\
\hline & & Control & $2.44 \pm .99$ & $2.37 \pm .52$ & & \\
\hline & \multirow{2}{*}{$\begin{array}{c}\text { Average pressure } \\
\left(\mathrm{N} / \mathrm{cm}^{2}\right)\end{array}$} & Experimental & $.46 \pm .05$ & $.49 \pm .03$ & \multirow{2}{*}{.90} & \multirow[t]{2}{*}{.38} \\
\hline & & Control & $.46 \pm .05$ & $.46 \pm .07$ & & \\
\hline \multirow{4}{*}{ Rt } & \multirow{2}{*}{$\begin{array}{c}\text { Maximum pressure } \\
\left(\mathrm{N} / \mathrm{cm}^{2}\right)\end{array}$} & Experimental & $2.50 \pm .41$ & $2.50 \pm .39$ & \multirow{2}{*}{-1.38} & \multirow[t]{2}{*}{.19} \\
\hline & & Control & $2.09 \pm .51$ & $2.46 \pm .68$ & & \\
\hline & \multirow{2}{*}{$\begin{array}{l}\text { Average pressure } \\
\left(\mathrm{N} / \mathrm{cm}^{2}\right)\end{array}$} & Experimental & $.48 \pm .04$ & $.49 \pm .03$ & \multirow{2}{*}{.00} & \multirow[t]{2}{*}{1.00} \\
\hline & & Control & $.44 \pm .08$ & $.45 \pm .05$ & & \\
\hline
\end{tabular}

$\mathrm{Lt}=$ Left, Rt=Right, † Significant differences between pre-test and post-test,

$* p<.05$ (=Significant differences between Experimental group and control group)

increase in the \%MVIC for plantar flexion in both feet; however, the value was not of statistical significance. In the control group, the \%MVIC was not significant, although it was still observed to have decreased. This is due to post-stretching which causes muscle elasticity (Kokkonen et al., 1998), twitch force output (Fowles et al., 2000), and the Golgi-tendon reflex (Rosenbaum and Henning, 1995) to change and thus reducing the muscle strength.
A comparison between the two groups revealed that there were no significant differences between the right and left feet; however, the elastic band exercise program was observed to be relatively more effective in increasing the $\%$ MVIC than the stretching exercise program. In terms of dorsiflexion, neither the experimental nor the control group showed significant results upon a comparison within the groups. The control group, wherein stretching was 
performed, was confirmed to have a more increased $\%$ MVIC than the experimental group. This was the case because the wearing of high heels causes the gastrocnemius and soleus to shorten and, as a consequence, the length-tension relationship of the muscles changes and the force of the muscle contractions is reduced, while the ability to generate force is also limited (Gefen et al., 2002; Gimmon et al., 2011; Lee et al., 2009). It is understood that the results of this study were due to the stretching exercise program re-lengthening the shortened muscle. A comparison between the groups showed that no significant changes occurred in either foot. In terms of inversion, a comparison within both groups showed that there was a significant change in both sides of the feet; however, between the groups there were no differences in the results. In a prior study that conducted an electromyographic analysis of the ankle joint muscles when on top of a partial footplate (Han et al., 2006), the highest amount of activity was observed in the tibialis. These findings were similar to the results of a previous study that used BAPS (Soderberg et al., 1991), which also found the highest amount of activity to be in the tibialis anterior. The tibialis anterior acts as the agonist during the inversion of the ankle (Kendall et al., 1993). In terms of eversion, a comparison within the groups showed that only the experimental group demonstrated a significant change in both feet. Within the control group and in a comparison between the two groups, no significant differences were revealed. These findings are similar to the results of a previous study wherein patients with unstable ankles were instructed to exercise on a wobble board, and the post-exercise results showed that the contraction time for the peroneus longus muscle had shortened (Clark and Burden, 2005). The peroneus longus muscle acts as an agonist during eversion (Kendall et al., 1993). As such, the experimental group which used a similar elastic band exercise program showed an overall more affected MVIC result than the control group. This may be explained by a previous study that reported resistance exercises using an elastic band enhanced muscle mass and stability by $10 \sim 27 \%$ as well as increased base physical stamina (Brill, 1995; Miskesky, 1994). It can be inferred that the strengthening of the ankle joint muscles leads to effective formation of ankle strategy and thus allowing for positive gains in balance.

In this study, plantar pressure was measured using Pedoscan. There was no difference in the maximum pressure between the experimental group and the control group. This is similar to Lee et al. (2012), where the preand post ankle muscle strengthening training showed no significant changes in the maximum pressure around the first metatarsal bone area. Furthermore, the average pressure also showed no difference in change for both the experimental and control group. In a previous study that measured the change in plantar pressure after using a TOGU (Kim and Lee, 2012), the pre-exercise data was $2.7 \mathrm{~N} / \mathrm{Cm} 2$ while the post-exercise data was $3.0 \mathrm{~N} / \mathrm{Cm} 2$, showing a slight improvement of flat feet. However, the lack of statistical significance was similar to the results of this study. Yet in a separate, longer study that was conducted for 12 weeks, three times a week (Kwon, 2014; Lim, 2014) the results showed change of significance. This was thought to be a result of the increased length of the experiment which allowed for a more exact performance of the exercise.

While the ankle muscle MVIC experienced positive change for both the elastic band and normal stretching group, the plantar pressure did not experience the same effects. In a previous study using a TOGU it was also noted that while there was a significant effect on balance, there were no effects noted on plantar pressure. In future studies, it is recommended that for a more clinically significant experiment, as suggested in a previous study (Kim et al., 2016), the study should last for 8 weeks, the daily life and personal exercise times should be completely restricted, and more individuals should take part in the study. 


\section{Conclusion}

The purpose of this study was to investigate the effects of the elastic band exercise program and the stretching exercise program on the change of plantar pressure and MVIC of the ankle muscles in female students wearing high heels. As a result, changes in plantar pressure and plantar flexion's MVIC were not changed in both groups, but both inversion's and eversion's MVIC showed improved results. In particular, exercise programs using elastic bands were not statistically significant but were more effective than exercise programs using stretching. In Dorsiflexion's MVIC, exercise program using stretching was not statistically significant but relatively effective than exercise program using elastic band. Therefore, it is suggested that exercise program using elastic band and exercise program using stretching can be an effective intervention method for MVIC of ankle joint muscles. Although the change of plantar pressure was not effective in this study, If the period and target number are secured, it is expected to have a positive effect.

\section{References}

Brill PA. The feasibility of conduction strength and flexibility programs for elderly nursing home residents with dementia. Gerontologist. 1995;35(2):263-6.

Clark VM, Burden AM. A 4-week wobble board exercise program improved muscle onset latency and perceived stability in individuals with a functionally unstable ankle. Physic Ther sport. 2005;6:181-7.

Clifford AM, Holder-Powell H. Postural control in healthy individuals. Clin Biomech. 2010;25(6):546-51.

Dowling, Steele JR, Baur LA. Does obesity influence foot structure and plantar pressure patterns in prepubescent children. International Journal of Obesity and Related Metabolic Disorders. 2001;25(6):845-52.
Fowles JR, Sale DG, MacDougall JD. Reduced strength after passive stretching of the human plantar flexors. J Appl Physiol. 2000;89(3):1179-88.

Franklin ME, Chenier TC, Brauninger L, et al. Effect of positive heel inclination on posture. J Orthop Sports Phys Thera. 1995;21(2):94-9.

Gefen A, Megido-Ravid M, Itzchak Y, et al. Analysis of muscular fatigue and foot stability during high-heeled gait. Gait Posture. 2002;15(1):56-63.

Gimmon Y, Riemer R, Oddsson L, et al. The effect of plantar flexor muscle fatigue on postural control. J Electromyogr Kinesiol. 2011;21(6):922-8.

Gravante G, Russo G, Pomara C, et al. Comparison of ground reaction forces between obese and control young adults during quiet standing on a baropodometric platform. Clin Biomech. 2003;18(8):780-2.

Gribble PA, Hertel J, Denegar CR, et al. The effects of fatigue and chronic ankle instability on dynamic postural control. J Athl Train. 2004;39(4):321-9.

Han SW, Kwon MJ, Che YW, et al. Electromyographic analysis of ankle muscles according to unstable platforms. Journal of Coaching Development. 2006;8(2):231-9.

Jung DJ, Joo KC. The effects of resistance exercise by elastic band for improved to daily living physical fitness in old-age women. Exerc Sci. 2003;12(2):253-66

Kendall FP, McCreary EK, Provance PG. Muscles: testing and function $\left(4^{\text {th }}\right.$ ed). Philadelphia. Lippincott Williams and Wilkins. 1993.

Kim DS, Choi IS, Kim SY. The impact of lower extremity strengthening exercise with step box and elastic band on balance ability and lower extremity muscular strength in community-living elderly individuals. J Korean Soc Phys Med. 2016;11(1):11-21.

Kim K, Lee JH. Effect of heel-heights of shoe on balance in older women. Journal of Korea Sport Research. 2007;18(2):311-20.

Kim SJ, Lee KJ. The effect of TOGU exercise on the postural 
balance and foot pressure distribution. The Korean Academy of Physical Therapy Science. 2012;19(1): 9-15.

Ko PH, Hsiao TY, Kang JH, et al. Relationship between plantar pressure and soft tissue strain under metatarsal heads with different heel heights. Foot Ankle. 2009;30(11): 1111-6.

Kokkonen J, Nelson AG, Cornwell A. Acute muscle stretching inhibits maximal strength performance. Res Q Exerc Sport. 1998;69(4):411-5.

Kwon JE. The effects of pilates reformer exercise on women's foot pressure, sagittal alignment and forward head posture. Master's Degree. Chung Ang University. 2014.

Lee CM, Jeong EH, Andris F. Biomechanics effects of wearing high-heeled shoes. Int J Ind Ergon. 2001;28:321-6.

Lee ES. The effects of 8 week pilates' universal reformer training on body composition, strength of lower extremity and balance control ability of adult women. Master's Degree. Daejeon University. 2008.

Lee HO, Bae WS, Shin JW. A comparison of the trunk muscle activity according to the direction of upper extremity lifting using elastic band. J Korean Soc Phys Med. 2016;11(2):25-31.

Lee JH, Lee JH, Kwon WA, et al. The effect of ankle joint muscle strengthening training and static muscle stretching training on stroke patients' plantar pressure and gait. Journal of the Korea Academia- Industrial cooperation Society. 2012;13(3):1153-60.

Lee MH, Chang JS, Lee SY, et al. The effects of high-heeled shoes on static balance and EMG activity of lower extremity muscles for young women. J Korean Soc Phys Med. 2009;4(1):43-8.

Lim EJ. The effect of lower limb strengthening exercise and gait training on body balance, Foot pressure and Cobb's angle in high school female scoliosis patients with pelvic malignment syndrome. Master's Degree. Korea
National Sport University. 2014.

Miskesky AE. Efficacy of a home-based training program for adults using elastic tubing. Eur J Of Applied Phy. 1994;69:316-20.

Opila KA, Wagner SS, Schiowitz S, et al. Postural alignment in barefoot and high-heeled stance. Spine. 1988;13: $542-7$.

Park JS. The effect of high-heeled shoes on foot pain and postural imbalance for female university students at the department of air tourism and service. Master's Degree. Han seo University. 2016.

Rosenbaum D, Henning EM. The influence of stretching and warm-up exercise of Achilles tendon reflex activity. J Sports Sci. 1995;13(6):481-90.

Ryu JS. The effect of walking with high-heel shoes on local dynamic stability. The Korean Journal of Physical Education. 2010;49(1):445-55.

Seo JS. The effect of Thera-Band stretching exercise on range of motion and strength of the patients with ankle sprain. Master's Degree. Kook Min University. 2005.

Shin SW. Classification of foot types and analysis for pressure distribution according to the height of heel during walking. Doctor's Degree. Kei myung University. 1997.

Soderberg GL, Cook TM, Rider SC, et al. Electromyographic activity of selected leg musclature in subjects with normal and chronically sprained ankles performing on a BAPS board. Phys Ther. 1991;71(7):514-22.

Song JW, Kim SJ, Lee GH, et al. Evaluation of foot pressures and subjective discomfort ratings associated with sneakers, high heels, and kill heels. J Ergon Soc Korea. 2009;28(3):95-102.

Woodall WR, Welsh J. A biomechanical basis for rehabilitation programs involving the patellofemoral joint. J Orthop Sports Phys Ther. 1990;11(11):535-42.

Yaggie JA, McGregor SJ. Effects of isokinetic ankle fatigue on the maintenance of balance and postural limits. 
Arch Phys Med Rehabil. 2002;83(2):224-8.

Yoon HW, Lee SY, Lee HM. The comparison of plantar foot pressure in normal side of normal people, affected side and less affected side of hemiplegic patients during stance phase. J Korean Soc Phys Med. 2009; 4(2):87-92.
Yoon JG, Kim MK, Kim EH, et al. The analysis of lower limb muscle activity according to change weight and high-heeled height during walking. The Official Journal of the Korean Association of Certified Exercise Professionals. 2010;12(1):65-72. 